\title{
Ocular findings in Japanese children with Down syndrome: the course of visual acuity and refraction, and systemic and ocular anomalies
}

This article was published in the following Dove Press journal:

Clinical Ophthalmology

\author{
Tomoko Terai ${ }^{1,2}$ \\ Shohei Eda ${ }^{1,2}$ \\ Jun Sugasawa ${ }^{2}$ \\ Masahiro Tonari² \\ Junko Matsuo ${ }^{2}$ \\ Hidehiro Oku² \\ Tsunehiko $\mathrm{lkeda}^{2}$ \\ 'Department of Ophthalmology, \\ Shiga Medical Center for Children, \\ Moriyama-City, Shiga, Japan; \\ ${ }^{2}$ Department of Ophthalmology, \\ Osaka Medical College, Takatsuki-City, \\ Osaka, Japan
}

Purpose: To investigate the age-related development of refractive errors and changes of visual acuity (VA), and the systemic and ocular anomalies in Japanese children and young adults with Down syndrome (DS).

Design: Retrospective cohort study.

Subjects and methods: This study involved 222 Japanese children and young adults with DS (age range: 3 months to 19 years) seen at the Department of Ophthalmology, Shiga Medical Center for Children, Shiga, Japan. The subjects were divided into the following six age groups: 1) infant (age 0 to $<4$ years), 2) preschool (age 4 to $<7$ years), 3) lower primary-school grades (age 7 to $<10$ years), 4) upper primary-school grades (age 10 to $<13$ years), 5) junior high school (age 13 to $<16$ years), and 6 ) late teen/young adults (age 16 to $<20$ years). Through examination of the subjects' medical charts, we investigated the development and changes of refractive errors and VA, best-corrected VA (BCVA), and systemic and ocular anomalies.

Results: For vision testing, Teller Acuity Cards ${ }^{\mathrm{TM}}$ (Bernell Corporation) were used for the infants, and the Landolt ring was used for the school-age children. VA was found to develop with age. Mean BCVA was $0.19 \pm 0.17$ logarithm of the minimum angle of resolution (mean age: 11.3 \pm 3.2 years). Mean of refractive errors was hyperopia in the infant (2.2 22.4 diopters [D] OD, $2.4 \pm 2.5 \mathrm{D}$ OS), yet became myopia to the junior high school $(-0.3 \pm 4.4 \mathrm{D}$ OD, $-0.2 \pm 4.4 \mathrm{D}$ OS $)$. Conclusion: Our findings revealed that in children and in late-teen and young-adult subjects with DS, VA slowly develops and that refractive errors requiring correction exist and are difficult to examine.

Keywords: astigmatism, Down syndrome, hyperopia, refraction, visual acuity

\section{Introduction}

Down syndrome (DS) is the most common human chromosomal anomaly, and is reportedly associated with incidences of refractive error, amblyopia, strabismus, nystagmus, cataract, and other ocular disorders. ${ }^{1-14}$ DS subjects also have systemic anomalies and experience delay in development. Several studies have reported that children with DS are afflicted with below-normal visual acuity (VA), as well as refractive error. ${ }^{10-24}$

The purpose of this retrospective cohort study was to investigate and identify the developments of age-related changes of VA and refractive errors in Japanese children and young adults with DS.

\section{Subjects and methods}

This study involved 222 Japanese children and young adults with DS (113 males and 109 females) seen at the Department of Ophthalmology, Shiga Medical Center for 
Children, Moriyama-City, Shiga, Japan, from October 1988 to January 2016. The subjects age at initial medical examination ranged from 3 months to 10 years. All subjects were diagnosed as having DS through pediatric chromosomal analysis. The study protocols were approved by the Ethics Committee of the Institutional Review Board of Shiga Medical Center for Children, and this study was conducted in accordance with the tenets set forth in the Declaration of Helsinki. Prior written informed consent was obtained from all subjects. And the parents or legal representatives of any participants under the age of 18 provided written informed consent on their behalf.

For statistical analysis of the course of VA and refraction, the subjects were divided into the following six age groups: 1) infant (I) group (age 0 to $<4$ years), preschool (P) group (age 4 to $<7$ years), 2) lower primary school grades (LPSG) group (age 7 to $<10$ years), upper primary school grades (UPSG) group (age 10 to $<13$ years), junior high school (JHS) group (age 13 to $<16$ years), late-teen/youngadult (LTYA) group (age 16 to $<20$ years). The subjects underwent the examinations from 0 to 9 times during each of the above-described age periods.

In all subjects, ocular examinations including VA, motility (by use of the alternate cover uncover test), head-position anomalies, cycloplegic refraction, slit-lamp biomicroscopy, and ophthalmoscopy were performed. VA was evaluated and determined by Teller acuity cards (TAC) (Teller Acuity Cards'sM; Stereo Optical, Inc., Chicago, IL, USA), dot card for near-point vision, Morizane, single-symbol optotypes, and single Landolt ring test cards. The test results were calculated using logarithm of the minimum angle of resolution (logMAR). Next, we examined the relationship between best VA by Landolt ring and that of by spectacles. Best VA was chosen as the better VA among right, left, and binocular-vision subjects with latent nystagmus. The subjects were divided into the following three groups: 1) Group 1: subjects with good ability to wear glasses (ie, the ability to wear glasses on all school days or only on some school days), 2) Group 2: subjects who had difficulty wearing glasses (ie, inability to wear glasses, or ability to wear glasses $<1$ hour [uncorrected refractive errors]), and 3) Group 3: subjects with no refractive errors.

Cycloplegic refraction testing of the subjects was performed after instillation of cyclopentolate $1 \%$, atropine $1.0 \%$, or atropine $0.5 \%$ eye drops, and automatic refraction testing was performed by using the Topcon KR-8800 Auto-Kerato Refractometer (Topcon Corporation, Tokyo, Japan) or the Righton Retinomax 3 Refract Keratometer (Right Group,
Tokyo, Japan). Emmetropia was defined as greater than -1.0 diopters (D) and less than +1.0D. Myopia was defined as less than or equal to $-1.0 \mathrm{D}$, while hyperopia was defined as greater than or equal to $+1.0 \mathrm{D}$. Astigmatism was defined as greater than or equal to 1.0D. Additionally we defined amblyopia as $0.301 \log$ MAR at ages 3 and 4 and 0 logMAR at age 7 .

The statistical calculations were performed using the StatView statistical software package (SAS Institute, Cary, $\mathrm{NC}$, USA), and the statistical significance of each difference was determined by using analysis of variance. A $P$-value of $<0.05$ was considered statistically significant.

\section{Results}

\section{Systemic and ocular anomalies}

The overall incidence of ocular and systemic anomalies in our cohort of 222 subjects with DS is shown in Tables 1 and 2 . Strabismus was observed in 87 (39.2\%) of the 222 subjects. Of those 87 subjects, 57 had esotropia or accommodative esotropia, 39 had overelevation in adduction, and 22 had exotropia or intermittent exotropia. Nystagmus was observed in $46(20.7 \%)$ of the 222 subjects. Of those 46 subjects, 26 had latent nystagmus and 20 had jerk-type nystagmus. Head-position anomalies were observed in 32 (14.4\%) of the 222 subjects; ie, head-position anomalies were observed in strabismus ( $\mathrm{n}=25$ subjects), nystagmus ( $\mathrm{n}=19$ subjects), and atlanto-axial subluxation (AAS) ( $n=5$ subjects). Of

Table I Ocular anomalies (without refractive error)

\begin{tabular}{lll}
\hline Type of ocular anomaly & $\begin{array}{l}\text { No of } \\
\text { subjects }\end{array}$ & $\%$ \\
\hline Strabismus & 87 & 39.7 \\
Esodeviation & 57 & 25.7 \\
Overelevation in adduction & 39 & 17.6 \\
Exodeviation & 22 & 9.9 \\
Dissociated vertical deviation & 1 & 0.5 \\
Nystagmus & 46 & 20.7 \\
Latent nystagmus & 26 & 11.7 \\
Jerk type & 20 & 9.0 \\
Pendular type + jerk type & 9 & 4.1 \\
Pendular type & 9 & 4.1 \\
Head-position anomalies & 32 & 14.4 \\
Head tilt & 25 & 11.3 \\
Face turn & 13 & 5.9 \\
Chin up & 8 & 3.6 \\
Blepharoconjunctivitis & 29 & 13.1 \\
Lens opacities & 25 & 11.3 \\
Nasolacrimal duct obstruction & 12 & 5.4 \\
Tigroid fundus (diffuse type and partial type) & 80 & 36.9 \\
Peripapillary vascular abnormalities & 13 & 5.9 \\
Myelinated nerve fiber & 1 & 0.5 \\
\hline
\end{tabular}


Table 2 Systemic anomalies

\begin{tabular}{lll}
\hline Disease & No of & $\%$ \\
& subjects & \\
\hline Heart disease & 117 & 52.7 \\
Atrial septal defect & 39 & 17.6 \\
Ventricular septal defect & 26 & 11.9 \\
Patent ductus arteriosus & 25 & 11.7 \\
Atrioventricular septal defect & 22 & 9.9 \\
Endocardial cushion defect & 9 & 4.1 \\
Tetralogy of Fallot & 7 & 3.2 \\
Others & 20 & 9.0 \\
Hypothyroidism & 38 & 17.1 \\
Gastrointestinal disease & 9 & 4.1 \\
Duodenal atresia & 6 & 2.7 \\
Imperforate anus & 2 & 0.9 \\
Others & 3 & 1.4 \\
Otolaryngology disease & 38 & 17.1 \\
Middle otitis & 25 & 11.7 \\
Hearing loss & 9 & 4.1 \\
Others & 7 & 3.2 \\
Orthopedic disease & 32 & 14.4 \\
AAS & 6 & 2.7 \\
AAS (suspect) & 14 & 6.3 \\
Flat foot & 7 & 3.2 \\
Others & 6 & 2.7 \\
Cryptorchidism & 5 & 2.3 \\
Epilepsy & 4 & 1.8 \\
Others & & \\
Cryptorchidism, leukemia, anemia, & & \\
atopic dermatitis, and so on & & \\
\hline Abrevition & & \\
\hline
\end{tabular}

Abbreviation: AAS, atlanto-axial subluxation.

those 32 subjects, two had the combination of strabismus, nystagmus, and AAS, eleven had the combination of strabismus and nystagmus, two had the combination of strabismus and AAS, one had the combination of nystagmus and AAS, eleven had strabismus only, and seven had nystagmus only. None of the subjects had head-position anomaly in AAS without strabismus and nystagmus. In addition, of those 32 subjects, 25 had head tilt, 13 had face turn, and eight had chin up. Head tilt was observed in strabismus ( $\mathrm{n}=22$ subjects), nystagmus ( $\mathrm{n}=13$ subjects), and AAS ( $\mathrm{n}=4$ subjects). Of the 25 head-tilt subjects, 18 had overelevation in adduction, nine had esotropia, and nine had latent nystagmus. Of the 13 faceturn subjects, six had esotropia, six had latent nystagmus, and six had jerk-type nystagmus. Head-position anomalies were observed in five of the six AAS subjects. No head-position anomaly was found in subjects suspected as AAS.

All 222 subjects had the typical ocular features of DS, that is, slanting palpebral fissures, epicanthus, and epiblepharon. Blepharoconjunctivitis was observed in 29 subjects (13.1\%), lens opacities were observed in 25 subjects (11.5\%), and nasolacrimal duct obstruction was observed in 12 subjects (5.4\%). Fundus examination revealed tigroid fundus in 80 subjects (36.0\%). In all 222 subjects, no glaucoma, keratoconus, or Brushfield spots was observed.

Of the total 222 subjects, congenital heart disease was found in $52.7 \%$, hyperthyroidism was found in $17.1 \%$, otolaryngology disease was found in $17.4 \%$, and orthopedic disease was found in $14.4 \%$ (Table 2). The children had various systemic complications.

\section{Visual acuity}

The number of subjects in each group in which VA was examined is shown in Table 3. Subjects were followed every 1 year from 4 months old, and best VA and age (ie, the lowest of each group) were checked. The eyes of all subjects $>4$ years of age were examined.

Median subject age and VA card test results are shown in Table 4. In the I group, 204 subjects were examined, and VA testing was possible in 200 subjects. The median age of the I-group subjects was 3.0 years, and in 191 I-group subjects $(95.5 \%)$, response to TAC testing was possible. All subjects were able to be tested more than the P-group subjects.

The median age of the P-group subjects was 4.9 years. In 75 P-group subjects (42.4\%), response to TAC testing was possible, and $62 \mathrm{P}$-group subjects $(35.0 \%)$ were tested in Landolt. Most of the P-group subjects over 7 years of age were able to be tested in Landolt. The median age of the LPSG-group, UPSG-group, JHS-group, and LTYA-group subjects was 7.7, 11.3, 14.3, and 18.3 years, respectively.

The mean TAC VA in the right and left eyes of the I-group and P-group subjects was 1.21 $\pm 0.22 \operatorname{logMAR}$ OD and $1.21 \pm 0.24 \log$ MAR OS, and $0.98 \pm 0.24 \log$ MAR OD and $0.98 \pm 0.24 \log$ MAR OS, respectively (Table 5), and a significant difference in TAC VA was found between these two groups (right eye: $P=0.0046$; left eye: $P=0.0092$ ). The mean Landolt VA in the right and the left eyes of the P-group,

Table 3 The number of subjects in each age group and all subject data tested by VA cards and refraction

\begin{tabular}{lllllll}
\hline $\begin{array}{l}\text { Age } \\
\text { group }\end{array}$ & $\begin{array}{l}\text { Range } \\
\text { (yrs) }\end{array}$ & $\begin{array}{l}\text { All } \\
\text { (n) }\end{array}$ & $\begin{array}{l}\text { VA } \\
\text { (n) }\end{array}$ & $\begin{array}{l}\text { Mean } \pm \text { (yrs) } \\
\text { (yrs }\end{array}$ & $\begin{array}{l}\text { Refraction } \\
\text { (n) }\end{array}$ & $\begin{array}{l}\text { Mean } \pm \text { SD } \\
\text { (yrs) }\end{array}$ \\
\hline I & 0 to $<4$ & 204 & 200 & $1.7 \pm 1.0$ & 157 & $2.5 \pm 1.0$ \\
P & 4 to $<7$ & 177 & 177 & $5.3 \pm 0.9$ & 145 & $5.2 \pm 0.8$ \\
LPSG & 7 to $<10$ & 112 & 112 & $8.1 \pm 0.8$ & 92 & $8.0 \pm 0.7$ \\
UPSG & 10 to $<13$ & 70 & 70 & $11.2 \pm 1.0$ & 49 & $11.2 \pm 1.0$ \\
JHS & 13 to $<16$ & 46 & 46 & $14.4 \pm 1.2$ & 33 & $14.4 \pm 1.0$ \\
LTYA & 16 to $<20$ & 24 & 24 & $17.8 \pm 1.1$ & 17 & $18.7 \pm 1.0$ \\
\hline
\end{tabular}

Abbreviations: VA, visual acuity; yrs, years; $n$, number of subjects; I, infant; P, preschool; LPSG, lower primary school grades; UPSG, upper primary school grades; JHS, junior high school; LTYA, late-teen/young-adult. 
Table 4 Age group responses to VA card tests

\begin{tabular}{|c|c|c|c|c|c|c|c|c|c|c|c|}
\hline \multirow{2}{*}{$\begin{array}{l}\text { Age } \\
\text { group }\end{array}$} & \multirow{2}{*}{$\begin{array}{l}\text { Range } \\
\text { (yrs) }\end{array}$} & \multirow{2}{*}{$\begin{array}{l}\text { Median } \\
\text { age }(y r s)\end{array}$} & \multirow[t]{2}{*}{$\mathbf{N}$} & \multicolumn{2}{|c|}{ TAC } & \multicolumn{2}{|c|}{ Morizane } & \multicolumn{2}{|c|}{ Symbol } & \multicolumn{2}{|c|}{ Landolt } \\
\hline & & & & $n$ & $\%$ & $\bar{n}$ & $\%$ & $n$ & $\%$ & $n$ & $\%$ \\
\hline 1 & 0 to $<4$ & 3.0 & 200 & 191 & 95.5 & 3 & 1.5 & 6 & 3.0 & 0 & 0 \\
\hline$P$ & 4 to $<7$ & 4.9 & 177 & 75 & 42.4 & 10 & 5.6 & 30 & 16.9 & 62 & 35.0 \\
\hline LPSG & 7 to $<10$ & 7.7 & 112 & 8 & 7.1 & 3 & 2.7 & 16 & 14.3 & 85 & 75.9 \\
\hline UPSG & 10 to $<13$ & 11.3 & 70 & I & 1.4 & 0 & 0 & 4 & 5.7 & 65 & 92.9 \\
\hline JHS & 13 to $<16$ & 14.3 & 46 & I & 2.2 & 0 & 0 & I & 2.2 & 44 & 95.7 \\
\hline LTYA & 16 to $<20$ & 18.3 & 24 & 0 & 0 & 0 & 0 & I & 4.2 & 23 & 95.8 \\
\hline
\end{tabular}

Abbreviations: VA, visual acuity; TAC, Teller acuity cards, Teller Acuity Cards ${ }^{\circledR}$ II; Morizane, dot card for near point, Morizane; Symbol, single symbol optotypes; Landolt, single Landolt ring test cards; yrs, years; n, number of subjects; I, infant; P, preschool; LPSG, lower primary school grades; UPSG, upper primary school grades; JHS, junior high school; LTYA, late-teen/young-adult.

LPSG-group, UPSG-group, JHS-group, and LTYA-group subjects was $0.41 \pm 0.24 \log$ MAR OD and $0.43 \pm 0.21 \log$ MAR OS, $0.31 \pm 0.21 \log$ MAR OD and $0.33 \pm 0.21 \log$ MAR OS, $0.29 \pm 0.21 \log$ MAR OD and $0.30 \pm 0.23 \log$ MAR OS, $0.27 \pm 0.22 \log$ MAR OD and $0.29 \pm 0.28 \log$ MAR OS, and $0.35 \pm 0.29 \log$ MAR OD and $0.38 \pm 0.30 \log$ MAR OS, respectively. Significant differences in Landolt VA were found between the P-group and UPSG-group subjects (right: $P=0.0245$; left: $P=0.0163$ ), and between the P-group and JHS-group subjects (right: $P=0.0430$; left: $P=0.0163$ ).

The best VA in Landolt was investigated in subjects over 7 years of age (ie, 98 subjects) (Table 6), and the median subject age and best VA were $11.3 \pm 3.3$ years and $0.19 \pm 0.17$ $\log$ MAR, respectively. In Group 1, Group 2, and Group 3, the number of subjects was 74,8 , and 16 , respectively, and the mean VA was $0.19 \pm 0.17 \log \mathrm{MAR}, 0.34 \pm 0.13 \log \mathrm{MAR}$, and $0.08 \pm 0.10 \log M A R$, respectively.

\section{Refraction}

The refraction results of the subjects are shown in Table 7. In the I, P, LPSG, UPSG, JHS, and LTYA groups, the median age and number $(n)$ of subjects were $2.5 \pm 1.0$ years $(n=157)$, $5.2 \pm 0.8$ years $(\mathrm{n}=145), 8.0 \pm 0.7$ years $(\mathrm{n}=92), 11.2 \pm 1.0$ years $(n=49), 14.4 \pm 1.0$ years $(n=33)$, and 18.7 \pm 1.1 years $(n=17)$, respectively. In the I group, hyperopia was the primary disorder and was found in $\sim 80 \%$ of the subjects, while myopia was found to occur in $<10 \%$ of the subjects. In fact, hyperopia was the primary disorder in all groups. The percentage of myopia became nearly as much as that of hyperopia, and was $\sim 40 \%$ in the LTYA group.

The percentage of astigmatism ranged 71.0 81.4 in subjects under 7 years of age, yet rose to over 90 in the teenage subjects. In the I-group subjects, the mean spherical equivalent was $+2.2 \pm 2.4 \mathrm{D}$ OD and $+2.4 \pm 2.5 \mathrm{D}$ OS (Table 8 ). It decreased yearly, and became $-0.3 \pm 4.4 \mathrm{D}$ OD and $-0.2 \pm 4.4 \mathrm{D}$ OS in the JHS-group subjects. In the I-group subjects, the mean astigmatic powers were 1.5 $\pm 1.0 \mathrm{D}$ OD and 1.6 $\pm 1.1 \mathrm{D}$ OS. In the JHS-group subjects, it increased slightly to $2.2 \pm 1.0 \mathrm{D}$ OD and $2.2 \pm 1.2 \mathrm{D}$ OS. Significant differences in spherical equivalent were found between the I-group subjects and the LPSG-group, UPSG-group, JHS-group, and LTYA-group subjects (right: $P=0.0055,0.018,<0.0001$, and $<0.0001$, respectively; left: $P=0.0128,0.0033,<0.0001$, and $<0.0001$, respectively), between the P-group subjects and the UPSG-group, JHS-group, and LTYA-group subjects (right: $P=0.0190,<0.0001$, and 0.0004 , respectively; left: $P=0.0253,0.0001$, and 0.0005 , respectively), and between the LPSG-group subjects and the JHS-group and LTYA-group

Table 5 The course of VA (age groups and VA: logMAR)

\begin{tabular}{|c|c|c|c|c|c|c|c|c|c|}
\hline \multirow{2}{*}{$\begin{array}{l}\text { Age } \\
\text { group }\end{array}$} & \multirow{2}{*}{$\begin{array}{l}\text { Range } \\
\text { (yrs) }\end{array}$} & \multicolumn{2}{|l|}{ TAC } & \multicolumn{2}{|l|}{ Morizane } & \multicolumn{2}{|l|}{ Symbol } & \multicolumn{2}{|l|}{ Landolt } \\
\hline & & $\begin{array}{l}\text { Right } \\
\text { mean } \pm \text { SD }\end{array}$ & $\begin{array}{l}\text { Left } \\
\text { mean } \pm \text { SD }\end{array}$ & $\begin{array}{l}\text { Right } \\
\text { range }\end{array}$ & $\begin{array}{l}\text { Left } \\
\text { range }\end{array}$ & $\begin{array}{l}\text { Right } \\
\text { range }\end{array}$ & $\begin{array}{l}\text { Left } \\
\text { range }\end{array}$ & $\begin{array}{l}\text { Right } \\
\text { mean } \pm \text { SD }\end{array}$ & $\begin{array}{l}\text { Left } \\
\text { mean } \pm S D\end{array}$ \\
\hline I & 0 to $<4$ & $1.21 \pm 0.22$ & $1.21 \pm 0.24$ & $1.00 \sim 0.70$ & $1.00 \sim 0.70$ & $1.00 \sim 0.52$ & $1.00 \sim 0.40$ & NA & NA \\
\hline$P$ & 4 to $<7$ & $0.98 \pm 0.24$ & $0.98 \pm 0.24$ & $1.00 \sim 0.22$ & $1.00 \sim 0.22$ & $1.00 \sim 0.22$ & $1.00 \sim 0.22$ & $0.4 I \pm 0.24$ & $0.43 \pm 0.21$ \\
\hline LPSG & 7 to $<10$ & $1.09 \pm 0.26$ & $1.09 \pm 0.26$ & $1.30 \sim 0.22$ & $1.30 \sim 0.40$ & $1.00 \sim 0.13$ & $1.00 \sim 0.13$ & $0.3 I \pm 0.2 I$ & $0.33 \pm 0.21$ \\
\hline UPSG & 10 to $<13$ & 1.22 & 1.22 & NA & NA & $0.70 \sim 0.22$ & $0.70 \sim 0.22$ & $0.29 \pm 0.21$ & $0.30 \pm 0.23$ \\
\hline JHS & 13 to $<16$ & NA & NA & NA & NA & 0.70 & 0.70 & $0.27 \pm 0.22$ & $0.29 \pm 0.28$ \\
\hline LTYA & 16 to $<20$ & NA & NA & NA & NA & 0.70 & 1.00 & $0.35 \pm 0.29$ & $0.38 \pm 0.30$ \\
\hline
\end{tabular}

Abbreviations: VA, visual acuity; logMAR, logarithm of the minimum angle of resolution; TAC, Teller acuity cards, Teller Acuity Cards ${ }^{\circledR}$ II; Morizane, dot card for near point, Morizane; Symbol, single symbol optotypes; Landolt, single Landolt ring test cards; yrs, years; I, infant; P, preschool; LPSG, lower primary school grades; UPSG, upper primary school grades; JHS, junior high school; LTYA, late-teen/young-adult. 
Table 6 Best VA and glasses

\begin{tabular}{lllll}
\hline & Whole & $\begin{array}{l}\text { Group I: } \\
\text { good glasses } \\
\text { wearing }\end{array}$ & $\begin{array}{l}\text { Group 2: difficulty } \\
\text { with glasses wearing } \\
\text { (uncorrected } \\
\text { refractive errors) }\end{array}$ & $\begin{array}{l}\text { Group 3: no } \\
\text { refractive } \\
\text { errors }\end{array}$ \\
\hline $\begin{array}{l}\text { Years } \\
\text { (mean } \pm \text { SD) }\end{array}$ & $11.3 \pm 3.3$ & $11.3 \pm 3.3$ & $11.5 \pm 3.1$ & $10.5 \pm 3.2$ \\
No of subjects & 98 & 74 & 8 & 16 \\
LogMAR (mean \pm SD) & $0.19 \pm 0.17$ & $0.19 \pm 0.17$ & $0.34 \pm 0.13$ & $0.08 \pm 0.10$ \\
Range of logMAR & $0.0-0.699$ & $-0.079-0.699$ & $0.097-0.523$ & $0.0-0.398$ \\
\hline
\end{tabular}

Abbreviations: VA, visual acuity; logMAR, logarithm of the minimum angle of resolution.

subjects (right: $P=0.0291$ and 0.0326 , respectively; left: $P=0.0268$ and 0.0365 , respectively).

In regard to astigmatic power, significant differences were found between the I-group subjects and the LPSGgroup, UPSG-group, JHS-group, and LTYA-group subjects in the right eye $(P=0.0049,0.0007,0.0002$, and 0.451 , respectively), between the I-group subjects and the UPSGgroup and JHS-group subjects in the left eye ( $P=0.0023$ and 0.0019 , respectively), between the P-group subjects and the LPSG-group, UPSG-group, and JHS-group subjects in the right eye ( $P=0.0015,0.0067$, and 0.0020 , respectively), between the P-group subjects and the UPSG-group, JHSgroup, and LTYA-group subjects $(P=0.0016,0.0015$, and 0.0476 , respectively), and between the LPSG-group subjects and the UPSG-group and JHS-group subjects in the right eye $(P=0.0021$ and 0.0043 , respectively).

\section{Discussion}

Due to the development of advanced treatment pathways, the average life span of subjects with DS has increased to over 50 years of age. In addition, it has been reported that the development of appropriate medical treatment throughout the life span of the subject is important. ${ }^{1}$ At our medical center, the early group nursing system for DS was initiated in 1990, and the outpatient clinic for DS in our Department of Pediatrics was initiated in 2012. Pediatrics plays a key role in long-term health care, and there is a relationship between otolaryngology, orthopedics, and ophthalmology.

In the present study, the percentage of congenital heart diseases was 52.7. In a previous study, it was reported as being $~ 50 \%$, and with a high rate of anomaly. ${ }^{1}$ Gastrointestinal disorders and hypothyroidism account for numerous medical diseases. In this present study, AAS, which causes head-position anomalies, was observed in $2.7 \%$ of the subjects, nearly identical to the findings in a previous report. ${ }^{26}$ Our findings revealed that as well as for in infants, the need for proper treatment management of DS continues through youth.

The ocular abnormalities in subjects afflicted with DS have been widely reported and are very well known, ${ }^{2-15}$ and our data revealed similar findings to those in the published literature. The incidence of strabismus in our study was $39.2 \%$, and is similar to that reported in previous studies (ie, ranging $20 \%-40 \%$ ). Reportedly, esodeviation is more common than exodeviation (ie, ranging $58.1 \%-100.0 \%$ ). ${ }^{2-15}$ Of the 222 subjects in this present study, there were $57(65.5 \%)$ with esodeviation and $22(22.5 \%)$ with exodeviation. Thus, the percentage of subjects with exodeviation

Table 7 The course of refractive errors

\begin{tabular}{|c|c|c|c|c|c|c|c|c|c|c|c|c|c|c|c|c|c|c|c|c|c|}
\hline \multirow[t]{3}{*}{$\begin{array}{l}\text { Age } \\
\text { group }\end{array}$} & \multirow[t]{3}{*}{$\mathbf{n}$} & \multicolumn{4}{|c|}{$\begin{array}{l}\text { Hyperopia } \\
\text { ( } \geq+1.0 \mathrm{D})\end{array}$} & \multicolumn{4}{|c|}{$\begin{array}{l}\text { Emmetropia } \\
(>-1.0,<+1.0 \mathrm{D})\end{array}$} & \multicolumn{4}{|c|}{$\begin{array}{l}\text { Myopia } \\
(\leq-1.0 \mathrm{D})\end{array}$} & \multicolumn{8}{|c|}{$\begin{array}{l}\text { Astigmatism } \\
(\geq 1.0 \mathrm{D})(\geq 2.0 \mathrm{D})\end{array}$} \\
\hline & & \multicolumn{2}{|c|}{ Right } & \multicolumn{2}{|c|}{ Left } & \multicolumn{2}{|c|}{ Right } & \multicolumn{2}{|c|}{ Left } & \multicolumn{2}{|c|}{ Right } & \multicolumn{2}{|c|}{ Left } & \multicolumn{2}{|c|}{ Right } & \multicolumn{2}{|c|}{ Left } & \multicolumn{2}{|c|}{ Right } & \multicolumn{2}{|c|}{ Left } \\
\hline & & $\mathbf{n}$ & $\%$ & n & $\%$ & $\mathbf{n}$ & $\%$ & $\mathbf{n}$ & $\%$ & $n$ & $\%$ & $n$ & $\%$ & $\mathbf{n}$ & $\%$ & $\mathbf{n}$ & $\%$ & $\mathbf{n}$ & $\%$ & $\mathbf{n}$ & $\%$ \\
\hline I & 157 & 120 & 76.4 & 128 & 81.2 & 27 & 17.2 & 16 & 10.2 & 10 & 6.4 & 13 & 8.3 & 120 & 76.4 & 119 & 75.3 & 52 & 33.1 & 60 & 38.2 \\
\hline$P$ & 145 & 111 & 76.6 & 108 & 74.5 & 17 & 11.7 & 20 & 13.8 & 17 & 11.7 & 17 & 11.7 & 118 & 81.4 & 103 & 71.0 & 55 & 37.9 & 61 & 42.1 \\
\hline LPSG & 92 & 62 & 67.4 & 59 & 64.1 & 14 & 15.2 & 16 & 17.4 & 16 & 17.4 & 17 & 18.5 & 78 & 84.8 & 74 & 80.4 & 41 & 44.6 & 45 & 48.9 \\
\hline UPSG & 49 & 29 & 59.2 & 31 & 63.3 & 9 & 18.4 & 6 & 12.2 & 11 & 22.4 & 12 & 24.5 & 41 & 83.7 & 42 & 85.7 & 27 & 55.1 & 42 & 61.2 \\
\hline $\mathrm{JHS}$ & 33 & 14 & 42.4 & 15 & 45.4 & 7 & 21.2 & 6 & 18.2 & 12 & 36.4 & 12 & 36.4 & 30 & 90.9 & 30 & 90.9 & 20 & 60.6 & 21 & 63.6 \\
\hline LTYA & 17 & 8 & 47.1 & 7 & 41.2 & 3 & 17.6 & 3 & 17.6 & 6 & 35.3 & 7 & 41.2 & 16 & 94.1 & 16 & 94.1 & 9 & 52.9 & 10 & 58.8 \\
\hline
\end{tabular}

Abbreviations: D, diopters; n, number of subjects; I, infant; P, preschool; LPSG, lower primary school grades; UPSG, upper primary school grades; JHS, junior high school; LTYA, late-teen/young-adult. 
Table 8 The course of refractive errors

\begin{tabular}{|c|c|c|c|c|c|c|}
\hline \multirow{2}{*}{$\begin{array}{l}\text { Age } \\
\text { group }\end{array}$} & \multirow{2}{*}{$\begin{array}{l}\text { Range } \\
\text { (yrs) }\end{array}$} & \multirow{2}{*}{$\begin{array}{l}\text { Mean } \pm \text { SD } \\
\text { (yrs) }\end{array}$} & \multicolumn{2}{|c|}{ Spherical refraction (D) } & \multicolumn{2}{|c|}{ Cylindrical refraction (D) } \\
\hline & & & $\begin{array}{l}\text { Right } \\
\text { mean } \pm \text { SD }\end{array}$ & $\begin{array}{l}\text { Left } \\
\text { mean } \pm S D\end{array}$ & $\begin{array}{l}\text { Right } \\
\text { mean } \pm \text { SD }\end{array}$ & $\begin{array}{l}\text { Left } \\
\text { mean } \pm \text { SD }\end{array}$ \\
\hline 1 & 0 to $<4$ & $2.5 \pm 1.0$ & $2.2 \pm 2.4$ & $2.4 \pm 2.5$ & $1.5 \pm 1.0$ & $1.6 \pm 1.1$ \\
\hline$P$ & 4 to $<7$ & $5.2 \pm 0.8$ & $2.0 \pm 2.7$ & $2.1 \pm 2.7$ & $1.62 \pm 1.0$ & $1.5 \pm 1.1$ \\
\hline LPSG & 7 to $<10$ & $8.0 \pm 0.7$ & $1.2 \pm 3.3$ & $1.5 \pm 3.4$ & $1.8 \pm 1.0$ & $1.8 \pm 1.1$ \\
\hline UPSG & 10 to $<13$ & $11.2 \pm 1.1$ & $0.8 \pm 3.8$ & $1.0 \pm 3.6$ & $2.1 \pm 1.2$ & $2.1 \pm 1.1$ \\
\hline JHS & 13 to $<16$ & $14.4 \pm 1.0$ & $-0.3 \pm 4.4$ & $-0.2 \pm 4.4$ & $2.2 \pm 1.0$ & $2.2 \pm 1.2$ \\
\hline LTYA & 16 to $<20$ & $18.7 \pm 1.0$ & $-0.7 \pm 4.8$ & $-0.5 \pm 4.8$ & $2.0 \pm 0.8$ & $2.1 \pm 0.8$ \\
\hline
\end{tabular}

Abbreviations: D, diopters; yrs, years; I, infant; P, preschool; LPSG, lower primary school grades; UPSG, upper primary school grades; JHS, junior high school; LTYA, late-teen/young-adult.

was higher than that reported in previous studies (range: $0 \%-20 \%$ ). It has been reported that it is $41.9 \%$ in Korean children, ${ }^{6}$ and Asians are known to have a higher prevalence of exotropia. ${ }^{27,28}$ Japanese children have the same tendency. Moreover, there have been numerous previous reports of hypertropia, ${ }^{2,4,5,8-10}$ with the percentage ranging from 1.3 to 8.9. In specific, the superior overelevation in adduction has reportedly been observed in few children, ${ }^{4,5,27}$ yet it was observed in 39 subjects $(44.8 \%)$ in this present study and was primarily related to the head tilt, which is one of the important elements in strabismus.

Numerous studies have reported the increased frequency of refractive errors and lower VA in subjects with DS. ${ }^{5,8,10-25}$ However, there have been few reports regarding changes related to patient age. ${ }^{5,8}$ The findings of this present study illustrate the age-related character of the ocular findings and the course of VA and refraction in Japanese subjects with DS.

In this study, TAC was the most useful testing method in the younger-age subjects, as it allowed us to recognize their developments. Landolt was able to be evaluated in children over 7 years of age, and significant differences were observed. Our findings showed a tendency for VA to decrease in young adults with DS, yet no significant differences were observed. Thus, it is important to keep a watchful eye on vision and ocular disorder in young adults afflicted with DS. In this study, we investigated the best VA in subjects with DS. Through the use of good glasses, we discovered that VA develops with age, and that children without refractive errors catch up with the age equivalency when $\sim 10$ years old.

It is widely reported that hyperopia is more common than myopia. ${ }^{4-6,8-10,13,15,17,18,22,24,25}$ In this study, we divided the subjects with DS into six age groups. Hyperopia was observed in the majority of the younger subjects, while myopia was seldom observed in infants. In accordance with hyperopia decreasing by aging, emmetropia and myopia increased.
The ratio of subjects with myopia became approximately the same as that of the subjects with hyperopia. In Japan, refraction in healthy infant children reportedly ranges $+1 \sim+3 \mathrm{D}$. Hyperopia decreases by age, and myopia usually occurs in school-age children. ${ }^{29}$ East Asians are known to have myopia, as well as the progression of myopia. ${ }^{30}$ Previous studies have reported that high myopia is one of the characteristics in subjects with DS. $2,5,7,10,11,18,22$ In the present study, we found that hyperopia was nearly constant in subjects under 7 years of age, and myopia began to increase in subjects over 7 years of age. Astigmatism was $71.0 \%$ 84.8\% in the children aged under 10 years, and over $90 \%$ in subjects in their late teens, that is, higher than that in the previous reports. Reportedly, the percentage of astigmatism ranges from 19 to $72.4 .^{5,6,8,10,14,18-20,22,24,25}$ However, the percentages in those studies were not even, as the standard value of the definition of astigmatism was not constant. High astigmatism, defined as more than 2.0D and 3.0D, has reportedly ranged from $29 \%$ to $59 \% .{ }^{5,6,14,20}$ In this study, the mean values were $1.5 \sim 2.2 \mathrm{DC}$ and the percentage of astigmatism defined as more than $2.0 \mathrm{D}$ was from 33 to 64 . Thus, it is nearly the same value as that reported previously. In this study, the children had astigmatism throughout childhood, and it was almost constant.

\section{Conclusion}

In conclusion, the findings of this clinical study show that in Japanese subjects with DS, there are many refractive errors and that VA progresses slowly through appropriate refractive management. In addition, our findings revealed the characteristics of DS in Japanese subjects, and illustrated that regular observation of vision and ocular disorders is important to improve the overall quality of life in children with DS.

\section{Acknowledgments}

The authors wish to thank F Nozaki, MD, E Ohta, MD, and T Hutami, MD, PhD, for suggesting the topic of Down 
syndrome and treatment protocol for the subjects. The authors also wish to thank N Noyama and M Oikawa for the visual function testing of the children in this study, and $\mathrm{J}$ Bush for editing the paper.

\section{Disclosure}

The authors report no conflicts of interest in this work.

\section{References}

1. Kliegman RM, Stanton BF, St Geme JW, Schor NF. Nelson Textbook of Pediatrics. 20th ed. Philadelphia: Elsevier; 2015.

2. Jaeger EA. Ocular findings in Down's syndrome. Trans Am Ophthalmol Soc. 1980;78:808-845.

3. Wong V, Ho D. Ocular abnormalities in Down syndrome: an analysis of 140 Chinese children. Pediatr Neurol. 1997;16(4):311-314.

4. Caputo AR, Wagner RS, Reynolds DR, Guo SQ, Goel AK, Syndrome D. Down syndrome. Clinical review of ocular features. Clin Pediatr. 1989; 28(8):355-358.

5. Tomita K, Tsurui H, Otsuka S, et al. Ocular findings in 304 children with Down syndrome. Nippon Ganka Gakkai Zasshi. 2013;117(9): 749-760.

6. Kim JH, Hwang JM, Kim HJ, Yu YS, Ys Y. Characteristic ocular findings in Asian children with Down syndrome. Eye. 2002;16(6):710-714.

7. Becerril-Carmona AF, Arroyo-Yllanes ME, Paciuc-Beja M. Alterations of ocular motility in Down syndrome. Am Orthopt J. 1997;47(1): 181-188.

8. da Cunha RP, Moreira JB. Ocular findings in Down's syndrome. Am J Ophthalmol. 1996;122(2):236-244.

9. Haugen $\mathrm{OH}, \mathrm{Høv}$ ding G. Strabismus and binocular function in children with Down syndrome. A population-based, longitudinal study. Acta Ophthalmol Scand. 2001;79(2):133-139.

10. Ljubic A, Trajkovski V, Stankovic B, Strabismus SB. Strabismus, refractive errors and nystagmus in children and young adults with Down syndrome. Ophthalmic Genet. 2011;32(4):204-211.

11. Yurdakul NS, Ugurlu S, Maden A. Strabismus in Down syndrome. J Pediatr Ophthalmol Strabismus. 2006;43(1):27-30.

12. Liza-Sharmini AT, Azlan ZN, Zilfalil BA. Ocular findings in Malaysian children with Down syndrome. Singapore Med J. 2006;47(1):14-19.

13. Akinci A, Oner O, Bozkurt OH, Guven A, Degerliyurt A, Munir K Refractive errors and strabismus in children with Down syndrome: a controlled study. J Pediatr Ophthalmol Strabismus. 2009;46(2):83-86.

14. Stirn Kranjc B. Ocular abnormalities and systemic disease in Down syndrome. Strabismus. 2012;20(2):74-77.
15. Mohd-Ali B, Mohammed Z, Norlaila M, Mohd-Fadzil N, Rohani CC, Mohidin N. Visual and binocular status of Down syndrome children in Malaysia. Clin Exp Optom. 2006;89(3):150-154.

16. Courage ML, Adams RJ, Reyno S, Kwa PG. Visual acuity in infants and children with Down syndrome. Dev Med Child Neurol. 1994;36(7): 586-593.

17. Tsiaras WG, Pueschel S, Keller C, Curran R, Giesswein S. Amblyopia and visual acuity in children with Down's syndrome. Br J Ophthalmol. 1999;83(10):1112-1114.

18. Stephen E, Dickson J, Kindley AD, Scott CC, Charleton PM. Surveillance of vision and ocular disorders in children with Down syndrome. Dev Med Child Neurol. 2007;49(7):513-515.

19. Paudel N, Leat SJ, Adhikari P, Woodhouse JM, Shrestha JB. Visual defects in Nepalese children with Down syndrome. Clin Exp Optom. 2010;93(2):83-90.

20. Ito F, Nakamura K, Hamamura M, et al. Refractive management and ocular complications in children with Down syndrome. Japanese Orthoptic Journal. 2009;38:177-184.

21. Little JA, Woodhouse JM, Lauritzen JS, Saunders KJ. The impact of optical factors on resolution acuity in children with Down syndrome. Invest Ophthalmol Vis Sci. 2007;48(9):3995-4001.

22. Berk AT, Saatci AO, Erçal MD, Tunç M, Ergin M. Ocular findings in 55 patients with Down's syndrome. Ophthalmic Genet. 1996; 17(1):15-19.

23. Woodhouse JM, Pakeman VH, Cregg M, et al. Refractive errors in young children with Down syndrome. Optom Vis Sci. 1997;74(10):844-851.

24. Haugen $\mathrm{OH}, \mathrm{Høv}$ ding G, Lundström I. Refractive development in children with Down's syndrome: a population based, longitudinal study. Br J Ophthalmol. 2001;85(6):714-719.

25. Fimiani F, Iovine A, Carelli R, Pansini M, Sebastio G, Magli A. Incidence of ocular pathologies in Italian children with Down syndrome. Eur J Ophthalmol. 2007;17(5):817-822.

26. Pueschel SM, Scola FH. Atlantoaxial instability in individuals with Down syndrome: epidemiologic, radiographic, and clinical studies. Pediatrics. 1987;80(4):555-560.

27. Lueder GT, Arthur B, Garibaldi D, Kodsi S, Kushner B, Saunders R. Head tilt-dependent esotropia associated with trisomy 21. Ophthalmology. 2004;111(3):596-599.

28. Jenkins RH. Demographics: geographic variations in the prevalence and management of exotropia. Am Orthopt J. 1992;42(1):82-87.

29. Nitta C, Kawamura H, Shuichi K, Masaaki N. Change in refractive states of hypermetropia in children. Folia Ophthalmol Jpn. 1991;42: $1560-1572$.

30. Sakakibara N. A review of age-related changes in refraction. Japanese Orthoptic Journal. 2013;42:41-49.
Clinical Ophthalmology

\section{Publish your work in this journal}

Clinical Ophthalmology is an international, peer-reviewed journal covering all subspecialties within ophthalmology. Key topics include: Optometry; Visual science; Pharmacology and drug therapy in eye diseases; Basic Sciences; Primary and Secondary eye care; Patient Safety and Quality of Care Improvements. This journal is indexed on Submit your manuscript here: http://www.dovepress.com/clinical-ophthalmology-journal

\section{Dovepress}

PubMed Central and CAS, and is the official journal of The Society of Clinical Ophthalmology (SCO). The manuscript management system is completely online and includes a very quick and fair peer-review system, which is all easy to use. Visit http://www.dovepress.com/ testimonials.php to read real quotes from published authors. 